\title{
Penggunaan Skor Pediatric Logistic Organ Dysfunction Harian sebagai Prediktor Mortalitas Anak yang Dirawat di Unit Perawatan Intensif Anak
}

\author{
Hendra Salim, Suparyatha IB, Budi-Hartawan I Nym \\ Bagian Ilmu Kesehatan Anak Fakultas Kedokteran Universitas Udayana/RS Sanglah, Denpasar
}

\begin{abstract}
Latar belakang. Penggunaan sistem skoring Pediatric Logistic Organ Dysfunction (PELOD) sebagai prediktor mortalitas anak yang dirawat di Unit Perawatan Intensif Anak (UPIA) di Indonesia masih belum banyak diteliti. Tujuan. Mengetahui hubungan skor PELOD harian dalam memprediksi mortalitas anak yang dirawat di UPIA. Metode. Penelitian observasional analitik terhadap 49 anak yang dirawat di UPIA bulan Maret-Juli 2012. Skor PELOD harian dinilai selama satu minggu pertama perawatan dan dibandingkan antara subyek hidup dan meninggal. Analisis statistik dikerjakan dengan menggunakan program komputer.

Hasil. Terdapat perbedaan nilai skor PELOD harian rendah, sedang, dan tinggi terhadap mortalitas anak yang dirawat di UPIA pada perawatan hari ketiga dengan $p=0,001$. Nilai skor sedang dan tinggi masingmasing berhubungan dengan peningkatan risiko mortalitas dengan RR 2,3 (1,09-5,02) dan RR 3,3 (1,0110,6). Rerata terjadinya mortalitas menurut analisis kurva Kapplan Meier pada skor rendah, sedang, dan tinggi masing-masing 23,12 dan 7 hari dengan $p=0,002$.

Kesimpulan. Skor PELOD harian dapat memprediksi mortalitas anak yang dirawat di UPIA dengan prediksi terbaik pada hari ketiga. Sari Pediatri 2014;16(2):141-6
\end{abstract}

Kata kunci: skor PELOD harian, kematian, UPIA.

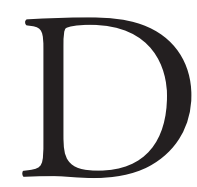

i Unit Perawatan Intensif Anak (UPIA), secara umum pasien dengan penyakit kritis ditandai dengan terganggunya homeostasis tubuh. Gangguan ini dapat

\footnotetext{
Alamat korespondensi:

Dr. Hendra Salim, Sp.A. Bagian/SMF Ilmu Kesehatan Anak Fakultas Kedokteran UNUD RSUP Sanglah Denpasar. Jl. Pulau Nias No. 1, Denpasar. Telp./Fax. (0361) 244038. E-mail: misionarispelayanan@ yahoo.com
}

diperkirakan dengan mengukur banyaknya variabel fisiologis yang nilainya di luar nilai normal. Besarnya gangguan ini memengaruhi lama rawat di UPIA dan prognosis anak.

Sistem skoring dibuat untuk menjelaskan penyakit saat awal dari kelompok pasien sakit kritis yang dirawat di UPIA. Skor ini menilai beberapa gangguan fisiologis dan ko-morbiditas saat masuk UPIA untuk memaksimalkan prediksi risiko mortalitas pasien. Gangguan fisiologis organ dicatat saat awal masuk 
hingga saat keluar dari UPIA. Luaran skor diharapkan dapat menjelaskan keparahan penyakit saat perawatan di UPIA. ${ }^{1}$

Sekarang ini, banyak dijumpai instrumen dalam memprediksi mortalitas anak yang dirawat di UPIA. Di seluruh dunia, khususnya di UPIA, sistem skoring yang paling sering digunakan adalah skor Pediatric Index of Mortality dan Pediatric Risk of Mortality yang dapat dipakai untuk membandingkan mortalitas yang diharapkan dengan mortalitas yang diobservasi. ${ }^{2}$ Studi di Brazil tahun 2005 menyimpulkan bahwa kedua sistem skoring ini memiliki kemampuan yang sama dalam hal evaluasi prognostik pasien anak yang dirawat di unit rawat intensif., 3

Sejak tahun 2003, PELOD harian mulai diperkenalkan dan telah beberapa kali mengalami validasi. Validitas dikatakan baik apabila diskriminasi dan kalibrasi memberikan hasil yang baik. Diskriminasi mengacu pada seberapa baik skor tersebut mendiagnosis atau memprediksi hasil akhir, sementara kalibrasi mengacu pada akurasi terhadap risiko prediksi. Dengan kalibrasi yang baik, apabila besaran skor menunjukkan risiko kematian $20 \%$ pada 100 orang, kita seharusnya dapat memprediksi 20 dari 100 orang tersebut akan meninggal..$^{5}$

Karena tidak mengukur risiko dalam skala kontinu, PELOD harian merupakan instrumen yang sulit dikalibrasi seperti yang diterapkan oleh sistem skor lainnya. Pediatric Logistic Organ Dysfunction harian menggunakan skor komposit dengan koefisien tunggal. Skala yang dihasilkan dari skor tersebut merupakan skala ordinal. ${ }^{5}$ Dengan keterbatasan tersebut, PELOD harian masih diminati karena mudah diaplikasikan dan menilai pada status vital pasien sehari-hari sehingga tidak menghabiskan banyak beban biaya bagi pasien. Dengan penilaian yang rutin, dapat ditentukan perubahan prognosis pasien tersebut selama perawatan di UPIA.

Di Indonesia, penelitian tentang sistem skoring sebagai prediktor mortalitas masih sedikit dan insiden kematian diperkirakan cukup tinggi. Biaya perawatan relatif mahal. Tenaga kerja yang kompeten untuk melakukan pencatatan nilai skoring tidak mencukupi. Dalam memprediksi mortalitas pasien, sistem skoring yang digunakan sebagai standar penilaian belum ada di UPIA Indonesia.

Skor PELOD merupakan sistem yang mudah diaplikasikan dan banyak digunakan di UPIA untuk menilai disfungsi organ pada anak. Penilaian skor
PELOD seringkali dilakukan pada hari pertama masuk UPIA dan tidak rutin dievaluasi setiap hari. Skor ini belum banyak digunakan untuk menilai mortalitas. Tujuan penelitian ini adalah untuk menilai hubungan skor PELOD harian terhadap mortalitas anak dengan penyakit kritis di UPIA RSUP Sanglah.

\section{Metode}

Penelitian observasional analitik dengan rancangan kohort retrospektif untuk mengetahui nilai parameter skor PELOD harian dalam memprediksi kematian anak yang dirawat di UPIA, Penelitian dilakukan di UPIA RS Sanglah Denpasar, Bali, mulai bulan Maret sampai Juli 2012. Populasi target adalah pasien anak yang menjalani rawat inap di UPIA RS Sanglah.

Sampel penelitian merupakan bagian dari populasi target yang memenuhi kriteria inklusi dan eksklusi. Besar sampel ditetapkan dengan $r=0,4, Z_{\alpha}=1,64$ dan $Z_{\beta}=0,84$, menggunakan rumus koefisien korelasi sehingga besar sampel minimal yang dibutuhkan adalah 38 sampel.

Pemilihan sampel dilakukan terhadap semua pasien yang dirawat di UPIA RS Sanglah secara berurutan sampai dengan jumlah sampel terpenuhi. Kriteria inklusi meliputi semua pasien yang menjalani rawat inap di UPIA RS Sanglah yang bersedia mengikuti penelitian dan menandatangani lembar persetujuan setelah penjelasan (PSP). Kriteria eksklusi yaitu pasien dengan lama perawatan di UPIA $<48$ jam, dirawat di UPIA atas indikasi observasi paska pembedahan, usia $>14$ tahun, dan pindahan dari UPIA lain. Pembedahan yang bersifat emergensi dan menyangkut keselamatan jiwa pasien (misalnya bulektomi pada paru anak dengan pneumonia sangat berat, evakuasi bekuan darah pada anak dengan perdarahan intrakranial luas yang mengalami penurunan kesadaran dan status epileptikus) tidak dieksklusikan.

Pasien anak yang memenuhi kriteria sebagai sampel penelitian akan diberikan PSP tentang penelitian. Orangtua menandatangani formulir persetujuan ikut serta dalam penelitian apabila setuju ikut dalam penelitian. Orangtua pasien akan ditanyakan mengenai karakteristik dasar pasien dengan menggunakan kuesioner terstruktur, meliputi riwayat penyakit, riwayat pengobatan, riwayat keluarga, riwayat tumbuh kembang, dan riwayat sosial. Pasien akan mendapatkan pemeriksaan menurut skor PELOD 
harian. Pemeriksaan dilakukan setiap hari oleh seorang dokter yang yang bertugas di UPIA.

Pemeriksaan menurut skor PELOD harian dilakukan dengan cara menghitung nilai skor pada variabel yang terbagi dalam enam organ besar, yaitu neurologis, kardiovaskular, ginjal, respirologi, hematologi, dan hepatologi. Setiap variabel memiliki skor $0,1,10$ atau 20. Skor maksimum untuk setiap organ adalah 20 dan skor maksimum untuk PELOD harian adalah 71 . Penelitian ini mengikuti pembagian skor PELOD harian menurut Leteurtre $\mathrm{dkk},{ }^{12}$ yaitu skor rendah (0-9), skor sedang (10-19), dan skor tinggi $(\geq 20)$.

Apabila terdapat variabel yang tidak dinilai pada hari tertentu maka diasumsikan nilainya sama dengan hasil pengukuran sebelumnya. Sementara itu, pada pengukuran variabel tertentu yang dilakukan lebih dari satu kali dalam 24 jam nilai skor PELOD harian yang diambil adalah skor tertinggi yang didapatkan.

Hasil penilaian akan dikumpulkan sampai tercapai luaran yang diharapkan saat pasien keluar dari UPIA, yaitu meninggal atau hidup. Semua data yang terkumpul akan dianalisis.

Karakteristik sampel penelitian disajikan dalam bentuk tabel dan dijelaskan secara naratif. Uji SaphiroWilk digunakan untuk menilai normalitas data. Nilai tengah dari skor PELOD harian dan lama rawat dihitung menurut kelompok usia. Analisis data dan kurva Kapplan Meier skor PELOD harian dihitung terhadap luaran kematian menggunakan program komputer.

\section{Hasil}

Selama periode bulan Maret - Juli 2012, terdapat 49 pasien yang memenuhi kriteria inklusi, terdiri dari 28 anak laki-laki dan 21 anak perempuan. Karakteristik sampel tersebut tertera pada Tabel 1. Subjek memiliki perbandingan jenis kelamin laki-laki lebih banyak daripada perempuan $(57 \%$ dan 43\%) dengan median usia 4 bulan dan lama perawatan 6 hari. Empatpuluh sembilan pasien mendapat perawatan, $29 \%$ meninggal dunia. Karakteristik kasus meninggal terbanyak disebabkan gangguan neurologis dan cedera yang memerlukan tindakan pembedahan.

Besar rerata skor PELOD pada luaran hidup cenderung menurun pada hari perawatan berikutnya, sementara pada luaran meninggal rerata skor PELOD semakin tinggi. Perbandingan skor PELOD harian terhadap luaran menunjukkan perbedaan yang bermakna terutama pada perawatan hari ketiga (Tabel 2).

Pada subyek penelitian, waktu terjadinya mortalitas ditampilkan dalam kurva Kapplan Meier (Gambar 1). Pada kurva, tampak kejadian mortalitas kelompok skor PELOD tinggi muncul sejak hari ketiga perawatan, sedangkan kelompok skor PELOD rendah-sedang mortalitas mulai tampak setelah empat hari perawatan. Rerata terjadinya mortalitas antara ketiga skor PELOD harian menurut analisis Kapplan Meier (Tabel 3) menunjukkan perbedaan yang bermakna dengan $\mathrm{p}=0,002$.

Tabel 1. Karakteristik sampel penelitian menurut luaran hidup dan meninggal

\begin{tabular}{lccc}
\hline Variabel & Hidup $(\mathrm{n}=35)$ & Meninggal $(\mathrm{n}=14)$ & Total $(\mathrm{n}=49)$ \\
\hline Jenis kelamin, laki-laki, n (\%) & $17(49)$ & $11(79)$ & $28(57)$ \\
Usia, bulan median (min-maks) & $4(1,1-91,9)$ & $17,8(1,7-124)$ & $6(1,1-124)$ \\
Lama rawat median (min-maks) & $6(3-26)$ & $4,5(2-11)$ & $5(2-26)$ \\
Ventilator mekanik n (\%) & $23(66)$ & $10(71)$ & $33(67)$ \\
Keluhan utama saat masuk UPIA, n (\%) & & & $11(23)$ \\
$\quad$ Neurologi & $7(20)$ & $4(29)$ & $7(14)$ \\
Kardiovaskular & $6(17)$ & $1(7)$ & $18(37)$ \\
Respirologi & $16(46)$ & $2(14)$ & $2(4)$ \\
Gastro-enterologi & $2(6)$ & $0(0)$ & $8(16)$ \\
$\quad$ Bedah & $4(11)$ & $4(29)$ & $1(2)$ \\
Infeksi tropis & $0(0)$ & $1(7)$ & $1(2)$ \\
$\quad$ Hemato-onkologi & $0(0)$ & $1(7)$ & $1(2)$ \\
Nefrologi & $0(0)$ & $1(7)$ & \\
\hline
\end{tabular}


Hendra Salim dkk: Penggunaan skor PELOD harian sebagai prediktor mortalitas anak yang dirawat di UPIA

Tabel 2. Perbandingan berbagai skor PELOD harian terhadap luaran sampel

\begin{tabular}{|c|c|c|c|c|c|}
\hline \multirow{2}{*}{ Nilai skor PELOD harian } & \multirow{2}{*}{ Hidup } & \multirow{2}{*}{ Meninggal } & \multirow{2}{*}{$\mathrm{RR}$} & $\mathrm{P}$ & IK95\% \\
\hline & & & & \multicolumn{2}{|c|}{ (Referensi) } \\
\hline \multicolumn{6}{|l|}{ Hari pertama } \\
\hline Rendah & 25 & 4 & 1 & & \\
\hline Sedang & 5 & 4 & 1,6 & 0,71 & $0,85-2,83^{*}$ \\
\hline Tinggi & 5 & 6 & 1,9 & 0,014 & $0,98-3,68^{*}$ \\
\hline \multicolumn{6}{|l|}{ Hari kedua } \\
\hline Rendah & 27 & 4 & 1 & 0,137 & \\
\hline Sedang & 5 & 3 & 1,4 & 0,001 & $0,80-2,42^{*}$ \\
\hline Tinggi & 3 & 7 & 2,9 & & $1,12-7,56^{*}$ \\
\hline \multicolumn{6}{|l|}{ Hari ketiga } \\
\hline Rendah & 29 & 2 & 1 & & \\
\hline Sedang & 4 & 6 & 2,3 & 0,001 & $1,09-5,02^{*}$ \\
\hline Tinggi & 2 & 5 & 3,3 & 0,001 & $1,01-10,6^{*}$ \\
\hline \multicolumn{6}{|l|}{ Hari keempat } \\
\hline Rendah & 19 & 2 & 1 & & \\
\hline Sedang & 6 & 3 & 1,4 & 0,143 & $0,84-2,20^{*}$ \\
\hline Tinggi & 2 & 5 & 3,2 & 0,004 & $0,97-10,3^{*}$ \\
\hline \multicolumn{6}{|l|}{ Hari kelima } \\
\hline Rendah & 17 & 1 & 1 & & \\
\hline Sedang & 3 & 3 & 1,9 & 0,035 & $0,84-4,24^{*}$ \\
\hline Tinggi & 2 & 3 & 2,4 & 0,021 & $0,80-6,95^{*}$ \\
\hline \multicolumn{6}{|l|}{ Hari keenam } \\
\hline Rendah & 14 & 1 & 1 & & \\
\hline Sedang & 2 & 3 & 2,3 & 0,032 & $0,79-6,89^{*}$ \\
\hline Tinggi & 2 & 1 & 1,4 & 0,314 & $0,62-3,15^{*}$ \\
\hline \multicolumn{6}{|l|}{ Hari ketujuh } \\
\hline Rendah & 13 & 2 & 1 & & \\
\hline Sedang & 3 & 1 & 1,2 & 0,53 & $0,63-2,10^{*}$ \\
\hline Tinggi & 1 & 2 & 2,6 & 0,108 & $0,52-13,04^{*}$ \\
\hline
\end{tabular}

* Uji Fisher's Exact

Tabel 3. Hasil analisis waktu mortalitas pada penilaian skor PELOD hari ketiga

\begin{tabular}{lccc}
\hline Skor PELOD hari ketiga & Mortalitas (hari) & Standar error & IK 95\% \\
\hline Skor rendah & 23 & 1,84 & $19,7-26,9$ \\
Skor sedang & 12 & 2,14 & $7,8-16,2$ \\
Skor tinggi & 7 & 2,27 & $3,3-12,2$ \\
\hline
\end{tabular}

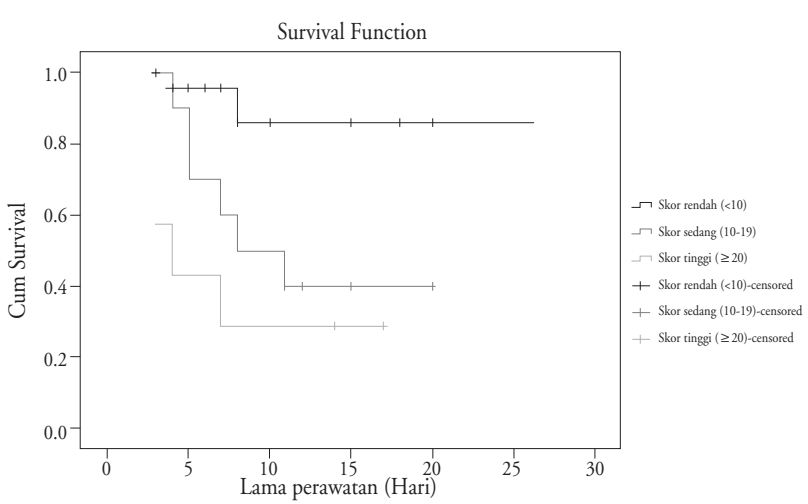

Gambar 1. Kurva Kapplan Meier

\section{Pembahasan}

Penelitian ini mendapatkan rerata mortalitas nilai skor PELOD rendah, sedang, dan tinggi berturut-turut 23, 12, dan 7 hari. Semakin tinggi nilai skor PELOD, semakin buruk prognosis pasien. ${ }^{9,10}$ Hasil ini sesuai dengan penelitian Metta $\mathrm{dkk}^{7}$ di RS Hasan Sadikin Bandung, rata-rata skor PELOD harian didapatkan pada penderita yang hidup $13,5(8,5)$ dan pada penderita yang meninggal 22,2 (10,1); $\mathrm{Z}_{\mathrm{M}-\mathrm{W}}=-2,507 ; \mathrm{p}=0,012$.

Ferraris dan Propp ${ }^{14}$ mendapatkan bahwa prediksi luaran pasien dewasa pada perawatan ruang intensif menjadi kurang akurat jika lama rawat melebihi 72 
jam. Leteurtre $\mathrm{dkk}^{12}$ mendapatkan akurasi penilaian PELOD harian cukup tinggi terutama dalam empat hari pertama perawatan. Pada pasien dewasa, LOD memiliki akurasi tinggi antara hari pertama sampai hari ketujuh. ${ }^{13}$ Penelitian ini mendapatkan hasil analisis yang bermakna pada perhitungan skor PELOD harian pada perawatan hari ketiga.

Perbedaan luaran skor PELOD harian setelah perawatan hari kelima pada penelitian ini mulai menurun, mungkin disebabkan semakin berkurangnya sampel karena cukup banyaknya luaran tercapai sebelum perawatan hari keenam. Pada hari keenam, sisa jumlah sampel separuh dari jumlah sampel awal.

Beberapa peneliti berpendapat bahwa penilaian skor yang dilakukan pada hari pertama dapat tersamar oleh pengobatan yang telah diberikan selama pasien anak masih di unit emergensi atau di ruangan dan belum masuk UPIA. Skor PELOD yang rendah pada hari pertama pada pasien anak yang meninggal berhubungan dengan keterlambatan masuk UPIA. Sebaliknya, beberapa pasien anak saat masuk UPIA memiliki skor yang lebih tinggi karena resusitasi tidak lengkap sebelumnya. ${ }^{15}$

Penelitian ini mengevaluasi penggunaan skor PELOD dalam memprediksi mortalitas dengan cara penilaian setiap hari sampai tercapai luaran. Penelitian ini memiliki kelemahan, yaitu jumlah sampel yang dimiliki setelah perawatan hari ketiga menjadi kurang dari jumlah sampel minimal diharapkan karena luaran meninggal yang cukup tinggi. Dengan demikian, penelitian kohort dengan melibatkan sampel yang cukup besar di kemudian hari diperlukan untuk mendapatkan validitas yang lebih tepat.

\section{Kesimpulan}

Skor PELOD harian dapat memprediksi mortalitas pasien anak yang dirawat di UPIA RS Sanglah Denpasar. Prediksi mortalitas skor PELOD harian sangat memuaskan apabila penilaian dilakukan pada perawatan hari ketiga. Setelah perawatan hari kelima, skor PELOD harian tidak dapat digunakan untuk memprediksi mortalitas.

\section{Daftar pustaka}

1. Lacroix J, Cotting J. Severity of illness and organ dysfunction scoring in children. Pediatr Crit Care Med
2005;6:S126-34.

2. Shann F, Pearson G, Slater A, Wilkinson K. Pediatric index of mortality (PIM): a mortality prediction model for children in intensive care. Intensive Care Med 1997;23:201-7.

3. Tibby SM. Does PELOD measure organ dysfunction and is organ function a valid surrogate for death? Intensive Care Med 2010;36:4-7.

4. Bertolini G, Ripamonti D, Cattaneo A, Apolone G. Pedatric risk of mortality: an assessment of its performance in a sample of 26 Italian intensive care units. Crit Care Med 1998;26:1427-32.

5. Castellanos-Ortega A, Delgado-Rodriguez M, Llorca J, Sanchez-Buron P, Mencia-Bartolome S, Soult-Rubio A. A new prognostic scoring system for meningiococcal septic shock in children. Comparison with three other scoring systems. Intensive Care Med 2002;28:341-51.

6. Winiarti E, Kosim MS, Supriatna M. Predicting PICU patient survival prognosis: Pediatric logistic organ dysfunction vs pediatric index of mortality scores. Pediatr Indones 2012;52:165-9.

7. Metta D, Subarja D, Somasetia DH. The use of pediatric logistic organ dysfunction (PELOD) scoring system to determine the prognosis of patients in pediatric intensive care units. Paediatr Indones 2006;46:1-6.

8. Madiyono B, Moeslichan S, Sastroasmoro S, Budiman I, Purwanto SH. Perkiraan besar sampel. Dalam: Sastroasmoro S dan Ismael S, penyunting. Dasar-dasar metodologi penelitian klinis. Jakarta: Sagung Seto; 2008.h. 302-31.

9. Hendra, Runtunuwu AL, Manoppo JIC. Pediatric logistic organ dysfunction (PELOD) score as prognosis of multiple organ failure in sepsis. Paediatr Indones 2010;50:226-31.

10. Honna L, Triratna S, Triwani, Theodorus. Use of pediatric logistic organ dysfunction (PELOD) in determining prognostic among pediatric intensive care unit patients. Paediatr Indones 2010;50:347-50.

11. Leteurtre S, Martinot A, Duhamel A, Proulx F, Grandbastien B, Cotring J, dkk. Validation of the paediatric logistic organ dysfunction (PELOD) score: prospective, observational, multicentre study. Lancet 2003;362:192-7.

12. Leteurtre S, Duhamel A, Grandbastien B, Proulx F, Cotting J, Gottesman R, dkk. Daily estimation of the severity of multiple organ dysfunction syndrome in critically ill children. CMAJ 2010;182:1181-7.

13. Timsit JF, Fosse JP, Troche G, De Lassence A, Alberti C, Garrouste-Orgeas M, dkk. Calibration and discrimination 
by daily logistic organ dysfunction scoring failure assessment scoring for predicting hospital mortality in critically ill patients. Crit Care Med 2002;30:2003-13.

14. Ferraris VA, Propp ME. Outcome in critical care patients: a multivariate study. Crit Care Med 1992;20:967-76.
15. Marlina L, Hudaya DS, Garna H. Perbandingan penggunaan pediatric index of mortality 2 (PIM2) dan skor pediatric logistic organ dysfunction (PELOD) untuk memprediksi kematian pasien sakit kritis pada anak. Sari Pediatri 2008;10:262-7. 